\title{
Stereotype Threat in U.S. Students Abroad: Negotiating American Identity in the Age of Trump
}

\section{Susan B. Goldstein}

University of Redlands

\begin{abstract}
:
An underinvestigated and significant source of stress for U.S. student sojourners across racial/ethnic groups is exposure to stereotypes that target their American identity. This study built on the extensive research literature on stereotype threat to investigate U.S. students' vulnerability and reactions to being the target of stereotypes. Stereotype threat occurs when one expects to be judged negatively based on stereotypes of one's social group and when one feels at risk of confirming these stereotypes. An online questionnaire administered to 95 students studying abroad just prior to and following the 2016 U.S. presidential election assessed predictors of, and common responses to, stereotype threat. Multiple regression analysis identified participant gender, motivational cultural intelligence (which involves attention and energy directed toward cultural differences), and exposure to Trump-related stereotypes as significant predictors of stereotype threat. Exploratory analyses indicated possible responses to stereotype threat, including distancing one's self from a U.S. American identity and altering one's appearance and behavior to look less American. Implications for sojourner support and for future research are discussed.
\end{abstract}

\section{Introduction}

U.S. students abroad across racial/ethnic groups report that the expectation and experience of being stereotyped as an American is a significant source of stress (Dolby, 2004; Gieser, 2015; Schwartz et al., 2012). This is likely due in part to the effect of such stereotypes on students' emerging and dynamic sense of identity. As Dolby (2004, p. 150) stated, “...study abroad provides not only the possibility of encountering the world, but of encountering oneself-particularly one's national identity - in a context that may stimulate new questions and new formulations of that self." Student sojourners may be particularly vulnerable to identity-based sources of stress since the average age of study abroad is a time of significant identity development (Savicki \& Cooley, 2011) and students often fail to anticipate the changes in identity that may result from their experiences abroad (Goldstein \& Keller, 2015). For these students, the ability to successfully navigate issues of national identity is associated with indices of psychological adjustment and well-being (Savicki \& Cooley, 2011). Understanding the role of national identity stereotypes abroad would enable study abroad professionals to provide students with targeted training and support. Yet little is known about the circumstances that contribute to sensitivity to stereotyping or the behavioral responses, if any, that accompany this experience. 


\section{Stereotype Threat}

A useful framework for understanding responses to stereotyping comes from the research literature on stereotype threat. Stereotype threat occurs when one expects to be judged negatively based on stereotypes of one's social group and feels at risk of confirming these stereotypes (Steele, Spencer, \& Aronson, 2002). According to Spencer, Logel, and Davies (2016, p. 417), “...stereotype threat arises from any situational cue indicating that an individual is at risk of being judged in light of a negative stereotype about one of his or her social identities." Although the vast majority of research on stereotype threat focuses on implications for task and academic performance, stereotype threat may also result in an increased likelihood of withdrawing from the threatened domain and a diminished sense of enjoyment and self-efficacy within that setting (Spencer, Logel, \& Davies, 2016). In a study abroad context, this may mean that students fail to fully engage with members of the host culture or have greater negativity about their overall experience abroad.

\section{Predictors of Stereotype Threat.}

An extensive body of research has identified factors both internal and external to the individual that are associated with vulnerability to stereotype threat. Internally, the stronger one's identification with the targeted group, the greater the likelihood of stereotype threat, as demonstrated in studies of self-identification based on race (Ployhart, Ziegert, \& McFarland, 2003), gender (Schmader, 2002), and academic discipline (Walton \& Cohen, 2003). Thus, student sojourners with a strong attachment to an American identity may be most vulnerable to stereotype threat when exposed to stereotypes focused on the U.S. and Americans. Externally, stereotype threat increases with the visibility of one's group within the social situation (Inzlicht \& Ben-Zeev, 2000; Sekaquaptewa \& Thompson, 2003), and therefore it seems likely that student sojourners who are unable to blend in as a member of the host culture environment may be at an increased risk for stereotype threat. Thus, the following hypotheses were proposed:

H1: Stronger U.S. American identity prior to study abroad will be associated with greater stereotype threat.

H2: Greater perceived visibility in the host culture will be associated with greater stereotype threat.

In addition to assessing the role of students' national identity and visibility in predicting stereotype threat, a major focus of this study was to investigate the impact of the current sociopolitical climate on stereotype threat vulnerability. Given the time frame for this study, just prior to, and following, the 2016 U.S. presidential election, and the empirical (Dolby, 2004) and anecdotal (e.g., Villarreal, 2016) evidence that stereotyping of U.S. sojourners increases in the presence of major domestic events with international implications, it seems likely that stereotype threat for U.S. sojourners would be exacerbated by election-related stereotyping. In fact, anecdotal evidence suggests that the rise and subsequent presidency of Donald Trump has resulted in a stressful situation for many U.S. Americans traveling and studying abroad, regardless of political affiliation. It is not surprising that election-related stereotyping is stressful for students across the political spectrum. A similar pattern was observed among U. S. Americans abroad following the 9/11 attacks, in which even supporters of the Bush administration reported discomfort with inquiries about the U.S. government's actions (Sato, 2009). 
Kauffman (2016) observed, "As the world watched the US presidential election, American students studying in Europe took it upon themselves to combat stereotypes, ease fears, and provide a more nuanced understanding of Donald Trump's victory." Statements from student bloggers and interviewees further suggest a likely effect of Trump-related stereotypes on U.S. students' experiences abroad:

When you're abroad, everyone keeps asking you about Trump. (Boyce, 2016)

Uncomfortable... is nowhere near a strong enough word to explain the way I feel when I am instantly connected with the name "Donald Trump." (Berger, 2016)

Stereotypes of Americans were common, but most prominent was conversation around U.S. politics... The main question I get asked is about what I think about Trump (Sturm, 2017).

I find it embarrassing ... I'm always having to distance myself from [Trump] with statements like, 'But I'm from California.' Or, 'I'm a first-generation American.' (Kennedy, 2016)

Thus, a central focus of the current study was to investigate whether individuals who have had more exposure to such stereotypes abroad will experience a greater degree of stereotype threat. The following hypothesis was proposed:

H3: Greater exposure to negative stereotypes of U.S. Americans in relation to the 2016 presidential election, specifically regarding the candidacy and presidency of Donald Trump, will be associated with greater stereotype threat.

Despite the increased risk for stereotype threat as a function of national identity, visibility, and exposure to Trump-related stereotypes, those individuals with the intercultural knowledge, skills and motivation to engage with members of the host culture beyond a superficial level, may find themselves less vulnerable to stereotype threat. In fact, it has been demonstrated that the ability to establish positive contact with members of the dominant group is associated with a reduction in stereotype threat (Abrams, Eller, \& Bryant, 2006; Walton, Logel, Peach, Spencer, \& Zanna, 2014). Thus, in the student sojourner situation, cultural intelligence may protect against the development of stereotype threat since cultural intelligence is a predictor of the ability to establish relationships with members of the host culture (Chen, Wu, \& Bian, 2014). On the other hand, students who are adjusting poorly to their new cultural environment and have diminished psychological resources may be particularly vulnerable to stereotype threat due to an inability to establish such relationships (Ward, Bochner, \& Furnham, 2001). Thus, the following hypotheses were proposed:

H4: Higher levels of cultural intelligence will be associated with lower stereotype threat.

H5: Lower levels of psychological well-being will be associated with greater stereotype threat.

In addition to determining factors that increase student sojourners' vulnerability to stereotype threat, an exploratory component of the current study focused on identifying common behavioral responses to the experience of stereotype threat.

\section{Responses to Stereotype Threat.}

Although research on the consequences of stereotype threat has focused almost entirely on implications for task performance, other responses aimed at "fending off the stereotype" (Block, 
Koch, Liberman, Merriweather, \& Roberson, 2011, p. 575) have been delineated. Several of these responses to stereotype threat are relevant to study abroad, including:

1. Disengaging by detaching one's identity from the threatened social group (Steele, Spencer, \& Aronson, 2002).

2. Distancing via efforts to demonstrate that one is not a typical member of their social identity group, often by behaving in a counterstereotypic manner (Block, Koch, Liberman, Merriweather, \& Roberson, 2011; Pronin, Steele, \& Ross, 2004; von Hippel, Walsh, \& Zouroudis, 2011).

3. Avoiding, or separating from, other members of the group (Block, Koch, Liberman, Merriweather, \& Roberson, 2011; Pronin, Steele, \& Ross, 2004; von Hippel, Walsh, \& Zouroudis, 2011).

4. Assimilating by passing as a member, or taking on the characteristics, of a more "highly regarded identity group” (Block, Koch, Liberman, Merriweather, \& Roberson, 2011, p. 577)

5. Challenging negative stereotypes by communicating favorable attributes of one's social identity group (Block, Koch, Liberman, Merriweather, \& Roberson, 2011).

Each of these possible responses to stereotype threat was investigated in the current study.

\section{Method}

This study received Institutional Review Board (IRB) approval and all procedures (e.g., recruitment, informed consent, confidentiality, debriefing, and data storage) were in compliance with IRB regulations and Ethical Principles of the American Psychological Association.

\section{Participants}

All 191 students studying abroad from a single institution during the fall 2016 and spring 2017 semesters were contacted with a request for participation and the link to an online questionnaire. They were informed that participants' names would be entered into a drawing for one of four Amazon gift cards. Over half of students at this institution participate in one of several study abroad options, including exported campus, direct enrollment, and hybrid programs. A total of 95 students $(50 \%)$ completed the questionnaire, including 15 male and 80 female undergraduate students (4.2\% sophomores, $88.4 \%$ juniors, and $7.4 \%$ seniors) in a wide variety of academic majors. None of these individuals identified as international students vis a vis the U.S. institution. They ranged in age from 19 to 22 years $(M=20.2)$ and were enrolled in study abroad programs in Europe (78.1\%), Asia (12.5\%), Australia (5.2\%), and Latin America (3.1\%). The questionnaire was administered during weeks 6-8 of the students' sojourn. Nearly all students (96\%) were enrolled in semester-long programs; the few enrolled in year-long programs were surveyed in their first semester only. In terms of race/ethnicity, the participants self-identified as 64.6\% White, 14.6\% Latino/a, 9.4\% Asian, 6.3\% Multiethnic, and 4.2\% Black. A total of $19.8 \%$ of participants reported speaking a language other than English at home and $81.3 \%$ had traveled outside of the United States prior to their study abroad experience, the majority of whom as tourists $(76.0 \%)$.

\section{Instruments and Procedure}

In addition to the demographic items and items developed by the author to assess study abroad program characteristics and travel experience, the questionnaire included the following: 
Stereotype Exposure.

Participants were asked in an open-ended item to list any positive or negative stereotypes of U.S. Americans that they had encountered while abroad. This item was subsequently used to create a variable indicating exposure to stereotypes related to the U.S. presidential election.

Stereotype Threat Measure.

Stereotype threat is generally defined as having two components: (1) the expectation that one's social group will be judged negatively, and (2) concern about confirming these negative stereotypes (Steele, Spencer, \& Aronson, 2002). Five items (Cronbach's alpha $=.71$ ) were developed by the author to assess the two components of stereotype threat: (1) I worry about acting like a stereotypical American; (2) People in my host culture generally view Americans negatively; (3) People in my host culture have a lot of negative stereotypes about Americans; (4) People in my host culture like Americans (reverse scored); and (5) I'm rarely the target of negative stereotypes of Americans (reverse scored).

Visibility Measure.

Two items (Cronbach's alpha $=.91$ ) were used to assess the participant's perception of their visibility in their host culture: (1) I stand out as a foreigner in my host culture, and (2) People can easily tell that I am not a member of the host culture. These items were embedded within the Stereotype Threat measure.

American Identity Measure. (AIM; Meyer-Lee \& Evans, 2008; Schwartz, et al., 2012).

Five items from the AIM identity affirmation subscale were used to assess identification with an American identity. These items were selected from the full AIM due to their direct relevance to the student sojourner experience. This measure consists of items adapted from the Multi-Group Ethnic Identity Measure (MEIM; Phinney \& Ong, 2007) and was designed for use with diverse ethnic/racial groups. It was found to have strong internal consistency, convergent and concurrent validity, and the factor structure was supported by confirmatory factor analysis (Schwartz, et al., 2012). Higher scores indicate stronger American identity. Participants were first directed to answer the items "based on how you felt BEFORE studying abroad" (PreAIM; Cronbach's alpha $=.95$ ) and then a second time "based on how you feel NOW" (PostAIM; Cronbach's alpha = .95). The PreAIM retrospective version was used as a predictor of stereotype threat, since it is the strength of one's identification with the target identity group upon encountering the stereotype that influences the level of stereotype threat (Ployhart, Ziegert, \& McFarland, 2003; Schmader, 2002). The change from PreAIM to PostAIM was subsequently computed to assess disengaging from an identity group, one of the strategies for responding to stereotype threat. Higher change scores indicate a greater decrease in strength of American identity.

Cultural Intelligence Scale. (CQS: Ang, Van Dyne, Koh, Ng, Templer, Tay, \& Chandrasekar, 2007).

The CQS is a 20-item measure of cross-cultural competence, which contains four subscales: (1) Motivational CQ - attention and energy directed toward cultural differences, (2) Cognitive CQ knowledge of cultural norms, practices, and conventions, (3) Metacognitive CQ - conscious cultural awareness during intercultural interactions, and (4) Behavioral CQ - ability to act appropriately during intercultural interactions in terms of verbal and nonverbal behavior. Higher scores indicate 
greater competence on each subscale. There is an extensive literature supporting the reliability, validity, and factor structure of this measure (e.g., Ang, Van Dyne, Koh, Ng, Templar, Tay, \& Chandrasekar, 2007; Matsumoto \& Hwang, 2013; Van Dyne, Ang, \& Koh, 2008; Van Dyne, Ang, $\mathrm{Ng}$, Rockstuhl, Tan, \& Koh, 2012). In the current study, these items yielded coefficient alphas of $.79, .86, .84$, and .78 for the Motivational, Cognitive, Metacognitive, and Behavioral subscales respectively.

Center for Epidemiologic Studies Depression Scale Revised. (CESD-R10; Eaton, Smith, Ybarra, Muntaner, \& Tien, 2004; Cronbach's alpha = $.75)$.

This ten item self-report measure assesses symptoms of depression in the general population. The items target symptoms of distress directly relevant to the student sojourner experience, such as loneliness, difficulty concentrating, and problems with sleep. It was found to have high internal consistency, test-retest reliability, and convergent validity (Miller, Anton, \& Townson, 2008; Radloff, 1977) and was used in the current study to assess sojourner well-being.

Responses to Stereotype Threat.

In addition to the Pre-PostAIM change score, which was used to assess disengaging from one's identity, participants were asked to respond to Likert scale items to indicate the frequency with which, while abroad, they (1) Identified with a different race/ethnicity, (2) Altered their appearance to look more American, (3) Altered their appearance to look less American, (4) Altered their behavior to look more American, (5) Altered their behavior to look less American, (6) Avoided other Americans, (7) Sought out other Americans, (8) Discussed positive aspects of the U.S., and (9) Discussed negative aspects of U.S. Item 1 assessed the Assimilating strategy, items 2-5 assessed the Distancing strategy, items 6 and 7 assessed the Avoiding strategy, and items 8 and 9 assessed the Challenging strategy. Each of these items was followed by an open-ended request to "please explain."

\section{Results}

\section{Stereotype Exposure}

Responses to the item on positive or negative stereotypes experienced while abroad were placed in general categories using SurveyMonkey text analysis. The most frequently stated stereotype of U.S. Americans was "loud" (34 participants), followed by "Trump supporter" or closely related terms, such as "Trump voter" (21 participants), "friendly/outgoing" (20 participants), "uneducated/ignorant" (17 participants), "rude/arrogant" (17 participants), consumers of "too much/unhealthy food" (12 participants), "drinking/partying" (9 participants) and "rich" (9 participants). A Trump stereotype variable was created for subsequent analyses, which was coded 0/1 depending on whether the participant indicated exposure to the "Trump supporter" stereotype in this open-ended item. Only one participant mentioned a U.S. presidential candidate other than Trump (Hillary Clinton) and did so in the context of describing exposure to the Trump supporter stereotype.

\section{Correlates and Predictors of Stereotype Threat}

Preliminary analyses were conducted to assess potential predictors of stereotype threat. Zero order correlations were computed for each of the predictor variables and the stereotype threat 
measure. Significant correlates of Stereotype Threat included Visibility, CQ-Motivation, and CQCognition (see Table 1). The CESD measure was eliminated from subsequent analyses due to its low correlation with the Stereotype Threat measure and comparatively lower theoretical relevance.

Table 1.Interscale Correlations for Stereotype Threat and Predictor Variables

\begin{tabular}{|c|c|c|c|c|c|c|c|c|c|}
\hline Variable & Mean & SD & 1 & 2 & 3 & 4 & 5 & 6 & 7 \\
\hline 1. Stereotype Threat & 3.94 & 0.97 & & & & & & & \\
\hline 2. PreAIM & 4.96 & 1.45 & .06 & & & & & & \\
\hline 3. Visibility & 4.57 & 1.55 & $.23 *$ & -.01 & & & & & \\
\hline 4. CQ-MOT & 5.99 & 0.74 & $-.33 * *$ & .07 & -16 & & & & \\
\hline 5. CQ- COG & 4.75 & 1.06 & $-.21 *$ & .03 & -.02 & $.55^{* *}$ & & & \\
\hline 6. CQ- META & 5.53 & 0.86 & -.06 & -.03 & .11 & $.44 * *$ & $.57 * *$ & & \\
\hline 7. CQ- BEH & 5.25 & 0.92 & .05 & -.10 & .09 & $.27 * *$ & $.39 * *$ & $.53 * *$ & \\
\hline 8. CESD & 2.32 & 0.44 & .05 & -.16 & .18 & $-.30 * *$ & -.08 & -.01 & .10 \\
\hline
\end{tabular}

A one-way Analysis of Variance (ANOVA) indicated that female participants $(\mathrm{M}=4.04, \mathrm{SD}=$ $0.95)$ scored significantly higher than male participants $(\mathrm{M}=3.39, \mathrm{SD}=0.82)$ on the Stereotype Threat measure $[\mathrm{F}(1,94)=6.08, \mathrm{p}<.01]$. Thus, participant gender was identified as a potential predictor of Stereotype Threat. Because the fall and spring semester waves of data collection preceded and followed the 2016 U.S. presidential election, analyses were conducted to determine whether semester of administration should be included as a variable in the analyses. Although stereotype threat scores were slightly higher in the spring $(\mathrm{M}=4.12, \mathrm{SD}=0.89)$ than fall $(\mathrm{M}=3.83$, $\mathrm{SD}=1.00)$ semesters, a one way ANOVA indicated that this difference was not statistically significant $[\mathrm{F}(1,94)=1.97, \mathrm{p}=\mathrm{NS}]$ and thus semester of administration was not included in subsequent analyses.

A hierarchical regression analysis was conducted to identify predictors of Stereotype Threat scores. Variance inflation factors (VIFs) indicated minimal multicollinearity in the data, with the highest VIF equal to 1.54 (for CQ-Motivation). The independent variables were entered in four discrete steps. Gender was entered in Step 1, the two identity-related variables, PreAIM and Visibility, were entered in Step 2, the four CQ subscales were entered in Step 3, and the Trump Stereotype variable was entered in Step 4 . Model 4 was statistically significant $(\mathrm{R}=.520$, adjusted $\mathrm{R} 2$ $=.187, \mathrm{~F}(8,78)=3.24, \mathrm{p}<.005)$, and accounted for approximately $27 \%$ of the variance in Stereotype Threat. Stereotype Threat was best predicted by Gender, CQ-Motivation (negatively), and exposure to Trump-related stereotypes (see Table 2). Visibility, while a significant predictor at Step 2, became nonsignificant with additional variables in the model. 
Table 2. Standardized beta coefficients of predictors of Stereotype Threat.

\begin{tabular}{|c|c|c|c|c|}
\hline \multirow{2}{*}{\multicolumn{5}{|c|}{ Model 1}} \\
\hline & & & & \\
\hline Gender & $.248^{*}$ & $.292 *$ & $.224 *$ & $.242^{*}$ \\
\hline \multicolumn{5}{|l|}{ Step 2: } \\
\hline PreAIM & & .116 & .138 & .191 \\
\hline Visibility & & $.253^{*}$ & .186 & .153 \\
\hline \multicolumn{5}{|l|}{ Step 3: } \\
\hline CQ-MOT & & & $-.272 *$ & $-.318 *$ \\
\hline CQ-COG & & & -.098 & -.042 \\
\hline CQ-META & & & .038 & .001 \\
\hline CQ-BEH & & & .125 & .161 \\
\hline \multicolumn{5}{|l|}{ Step 4: } \\
\hline Trump Stereotype & & & & $.239 *$ \\
\hline $\mathrm{R}^{2}$ & .061 & .137 & .220 & .270 \\
\hline $\mathrm{F}$ for $\Delta \mathrm{R}^{2}$ & & $3.268 *$ & 1.901 & $4.831 *$ \\
\hline
\end{tabular}
Note: $* \mathrm{p}<.05$.

\section{Responses to Stereotype Threat}

Exploratory correlations were conducted to identify possible responses to the experience of stereotype threat (See Table 3). Stereotype Threat scores were significantly correlated (positively) with change in Pre-PostAIM score, altering appearance to look less American, and altering behavior to look less American, and negatively correlated with discussing positive aspects of the U.S. with members of the host culture.

Table 3. Response Variable Means, Standard Deviations, and Correlations with Stereotype Threat.

\begin{tabular}{llll} 
Variable & Mean & SD & Correlation \\
\hline Stereotype Threat & 3.94 & 0.97 & \\
AIM Change & 0.42 & 1.15 & $.26^{* *}$ \\
Identified with different race/ethnicity & 2.28 & 1.53 & .15 \\
Altered appearance to look more American & 1.20 & 0.48 & .08 \\
Altered appearance to look less American & 2.79 & 1.67 & $.23^{*}$ \\
Altered behavior to look more American & 1.32 & 0.86 & .03 \\
Altered behavior to look less American & 2.80 & 1.61 & $.35^{* *}$ \\
Avoided other Americans & 1.99 & 1.34 & .02 \\
Sought out other Americans & 2.75 & 1.34 & .13 \\
Discussed positive aspects of U.S. & 3.55 & 1.39 & $-.22^{*}$ \\
Discussed negative aspects of U.S. & 3.39 & 1.36 & -.13 \\
\hline
\end{tabular}

Note: $* \mathrm{p}<.05, * * \mathrm{p}<.01$

\section{Discussion}

\section{Predictors of Stereotype Threat}

This study sought to investigate possible predictors of stereotype threat for student sojourners, including strength of U.S. American identity, perceived visibility within the host culture, exposure to Trump-related stereotypes, cultural intelligence and well-being. Contrary to H1, the strength of 
identification with U.S. American nationality prior to study abroad as measured by the PreAIM score was not a predictor of stereotype threat. This was surprising given robust findings in the research literature linking stereotype threat with strength of target group self-identification. One explanation for the lack of significant relationship between PreAIM and Stereotype Threat in the current study deals with the retrospective nature of that measure. It is possible that participants were unable to accurately recall their pre-departure feelings about their national identity, or that perceptions of their earlier identity were contaminated by their self-identification at the time of the survey. Future research would benefit from a longitudinal design in which national identity is assessed at different points in the student's sojourn. A second possible explanation for the lack of significant relationship between preAIM scores and Stereotype Threat comes from the finding that at times individuals who identify very strongly with a target group may be less susceptible to stereotype threat than those who identify at a more moderate level (Nguyen \& Ryan, 2008). It is possible that students who very strongly identify as U.S. Americans are better able to dismiss stereotypes or make external attributions for their content. In fact, there is some indication that external causal attributions play a role in mitigating performance-related outcomes of stereotype threat (Mclntyre, Paulson, Taylor, Morin, \& Lord, 2011; Smith, \& Hopkins, 2004). Although no significant curvilinear relationship between PreAIM and Stereotype Threat was found in the current study, future research might focus on the impact of different levels of national identity strength and the role of causal attributions in the development of stereotype threat.

H2 was partially confirmed, in that participants' perceived visibility in the host culture was a significant positive correlate of stereotype threat, although not a significant predictor in the final model of the regression analysis. Thus, there is some indication that those student sojourners who feel they are easily identifiable as foreigners may have increased vulnerability to stereotype threat. Self-perceived visibility was used in this study as a simple and straightforward measure of the participants' salience in the host culture given the multiple and diverse combinations of student race/ethnicity and host culture demographics represented in the sample. Future research might employ more sensitive measures of visibility that take into consideration such factors as host country homogeneity and normative attitudes regarding multiculturalism and cultural outsiders.

H3 was supported in that exposure to Trump-related stereotypes was a significant predictor of Stereotype Threat. This finding highlights the degree to which U. S. student sojourners' experiences abroad may be affected by perceptions of current events in the U. S., particularly when those events have international implications. Sato (2009, p. 217), in reference to the challenges faced by U. S. university alumni abroad in the immediate post $9 / 11$ years observed, “...occasionally students may find themselves to be participants in or observers of profound experiences caused by other external factors, which can potentially transform their perspectives and sense of self." Circumstances such as these may underscore the role of students abroad as ambassadors, a role for which they may feel unprepared. Predeparture training and in-country support programs might encourage U.S. students, regardless of political orientation, to investigate host culture perceptions of U.S. politics and policy and to prepare appropriate responses and coping strategies. Sato (2009) notes that increased ambivalence about national identity may not only affect students' intercultural adjustment abroad, but their well-being upon returning home. More research is needed on the role of sociopolitical climate on stereotype threat in order to provide study abroad professionals with specific recommendations for student training and support. 
H4 was partially confirmed in that the CQ-Motivation subscale was a significant predictor of stereotype threat. Due to the absence of an empirical literature on cultural intelligence and stereotype threat, no specific hypotheses were made about the individual CQ subscales in the current study. All four of the CQ subscales were expected to be negatively associated with stereotype threat. However, only CQ-Motivation was a significant (negative) predictor of stereotype threat. Several studies have found CQ-Motivation to be predictive of intercultural adjustment beyond that of the other CQ subscales (e.g., Huff, 2013; Templer, Tay, \& Chandrasekar, 2006). As an intercultural domain-specific form of self-efficacy (Early \& Ang, 2003), CQ-Motivation is associated with "persist[ence] in adapting to diverse cultural situations" as well as the ability to "adjust well in...interactions with those from different cultural backgrounds" (Templer, Tay, \& Chandrasekar, 2006, p. 159-160). Thus, it is reasonable that CQ-Motivation would encompass the qualities that allow sojourners to have positive interactions with members of the host culture, interactions that supersede more superficial experiences of being stereotyped. Although CQCognitive was a significant negative correlate of Stereotype Threat in the current study, it was not a predictor in the regression analysis, and CQ-Metacognitive and Behavioral were uncorrelated with Stereotype Threat. Additional research is needed to identify the specific types of cultural knowledge and skills most closely tied to stereotype threat. It is surprising that CQ-Metacognitive, in particular, was not a predictor of Stereotype Threat since it is the type of higher order cognitive process that this subscale represents that allows sojourners to view situations from a host culture perspective (Ng, Van Dyne, \& Ang, 2012).

H5 was not supported in that participants' level of psychological well-being as measured by the CESD was uncorrelated with stereotype threat. This is an area that warrants further investigation given the prevalence of mental health concerns among students abroad (Bathke \& Kim, 2016). In the current study, it may have been the case that the CESD scale tapped into more severe forms of psychological distress than would be typical of student sojourners. Future investigations of the role of student well-being in stereotype threat might use measures that target subclinical forms of psychological distress as well as those stressors specifically faced by students within a study abroad context.

\section{Responses to Stereotype Threat}

In the current study, stereotype threat was associated with several of the behaviors identified by Block, Koch, Liberman, Merriweather, and Roberson (2011, p. 575) as "fending off the stereotype." The primary strategies used by the student sojourners surveyed were Disengaging and Distancing. Study participants manifested Disengaging in that those with higher Stereotype Threat scores had a greater decrease in their AIM scores over the course of their time abroad. In other words, those facing stereotype threat based on being a U.S. American were more likely to show a decrease in national identity. Distancing was also evident in that participants with higher Stereotype Threat scores were more likely to alter their appearance and behavior to appear less American. For example, a student in London stated, "I've made an effort to dress similarly to the locals here in order to stand out less. I don't wear anything representing my home university or America in general." A student in Barcelona revealed, "I'll pretend to talk on the phone in Spanish so people don't target me as an American," and a student in Berlin wrote, "I don't want to be asked about Trump so I try not to stand out." 
Although for respondents overall there was no correlation between Stereotype Threat and identifying with another race/ ethnicity (Assimilating), this was a strategy that a significant number of Students of Color indicated that they used on occasion. A one way ANOVA found that Students of Color $(\mathrm{M}=3.00, \mathrm{SD}=1.76)$ scored significantly higher than White students $(\mathrm{M}=1.90, \mathrm{SD}=$ $1.26)$ in the frequency with which they identified with another ethnic group abroad $[\mathrm{F}(1,92)=$ 12.04, $\mathrm{p}<.005$ ]. For example, a student in Milan reported, "So many Europeans assume that I am from China that I sometimes don't bother to correct them." A student in Salamanca stated, "I tell people I'm from Mexico so that I don't get asked many questions." And a student in Granada disclosed, "I usually just say I'm African American but here I like to specify [that I am] Haitian."

In terms of Challenging the stereotype, contrary to prediction Stereotype Threat scores were inversely correlated with discussing positive aspects of the U.S. with members of the host culture, as was also the case with discussing negative aspects of the U.S., although in the latter case, not significantly so. In other words, those experiencing Stereotype Threat were less likely to discuss positive or negative aspects of the U.S. It may be the case that those experiencing stereotype threat may avoid discussing the U.S. altogether for fear of eliciting further stereotypes or negative portrayals in response. Along these lines, a student from Copenhagen wrote, "I usually mention what I like better about Denmark than the US, but I don't usually feel comfortable promoting the US in conversation unless specifically asked about something I like or miss. If something casually comes up I'm more likely to explain it than praise it." And a student in Florence reported, "Although I sometimes am not the most proud of the United States, I don't express that to members of my host culture." Meanwhile, it may be those with more favorable views of the U.S. who are discussing its positive aspects. A student in Salzburg, for example, stated, "I think America is an amazing place and I do not understand why people are not proud of being from America...so when America, or where I come from comes up, I will talk very highly of it because I am proud."

Finally, there was no evidence of an association between Avoiding and Stereotype Threat scores in that those with greater Stereotype Threat were no more likely to avoid other Americans or less likely to seek them out. It may thus be the case that for students abroad, contact with other members of one's own country is more a matter of their program's level of immersion than the individual's deliberate strategy. Although the scope of the current study did not allow for analyses by program type, this may be a worthwhile direction for future research.

There are several limitations to this study, including the use of a small, single-institution sample, and the brevity of some of the measures, the two-item visibility scale in particular. In addition, characteristic of study abroad overall, male participants were underrepresented in this sample. Because male students scored significantly lower than female students on Stereotype Threat, it would be useful to investigate whether this reflects gender differences in coping strategies or if perhaps greater sensitivity to stereotype threat is concomitant with the greater intercultural awareness manifested by female, as compared with male, students choosing to study abroad (Goldstein \& Kim, 2006). Future research might also include a more sensitive assessment of stereotype exposure, one which, for example, goes beyond the frequency of exposure to gauge the intensity of those events. Finally, although a major focus of this study was stereotype threat within the context of the 2016 U.S. presidential election, no data was collected on students' individual political attitudes or orientation, a variable which may moderate responses to stereotype threat. 
This study contributes to the call for research on stereotype threat in a wider variety of settings (Block, Koch, Liberman, Merriweather, \& Roberson, 2011) by demonstrating the presence of stereotype threat in a study abroad context. It suggests that study abroad professionals need to be cognizant of the conditions that result in greater vulnerability to stereotype threat for students abroad, including high profile current events, student visibility within the host country, and the students' level of cultural intelligence, particularly with regard to self-efficacy. Future research might focus on the clinical implications of stereotype threat within a study abroad context and its impact on the successful adjustment and well-being of student sojourners. In addition, it may be worthwhile to investigate implications of stereotype threat for student sojourners' academic and social performance, particularly when their national identity is salient, such as in a direct enroll context. Study abroad research might also investigate the possible implementation of strategies that have been successful for reducing stereotype threat in academic contexts, such as educating participants about the stereotype threat process (Johns, Schmader, \& Martens, 2005), and providing successful role models who are members of the targeted group (Drury, Siy, \& Cheryan, 2011; Shaffer, Marx, \& Prislin, 2013). The finding that CQ-Motivation was a strong predictor of stereotype threat suggests that training to increase intercultural self-efficacy may be another useful strategy for mitigating the effects of stereotype threat.

Finally, future research might explore the conditions under which stereotype threat, in its milder form, could be beneficial to U.S. students abroad. As Gieser (2015, p. 642) indicated, through crosscultural interaction, U. S. student sojourners come to realize that in addition to their own sense of national identity, "notions [of America and Americans] were constructed by persons situated outside American borders, as well." With guidance and support from study abroad professionals, stereotype threat may become a valuable opportunity for students to explore these multiple perspectives, gain intercultural awareness, and better understand their responsibilities as mindful travelers and global citizens.

\section{REFERENCES}

Abrams, D., Eller, A., \& Bryant, J. (2006). An age apart: the effects of intergenerational contact and stereotype threat on performance and intergroup bias. Psychology and Aging, 21(4), 691-702,

Ang, S., Van Dyne, L., Koh, C. S. K., Ng, K. Y., Templer, K. J., Tay, C., \& Chandrasekar, N. A. (2007). Cultural intelligence: Its measurement and effects on cultural judgment and decision making, cultural adaptation and task performance. Management and Organization Review, 3(3), 335-371.

Bathke, A., \& Kim, R. (2016). Keep calm and go abroad: The effect of learning abroad on student mental health. Frontiers: The Interdisciplinary Journal of Study Abroad, 27, 1-16.

Berger, M. (2016, November 4). Places where people have asked me about Donald Trump. IES Abroad Study Abroad Blogs. Retrieved from https://www.iesabroad.org/studyabroad/blogs/mdbergergwuedu/places-where-people-have-asked-me-about-donaldtrump\#sthash.RirDClmK.dpbs.

Block, C. J., Koch, S. M., Liberman, B. E., Merriweather, T. J., \& Roberson, L. (2011). Contending with stereotype threat at work: A model of long-term responses. The Counseling Psychologist, 39(4), 570600.

Boyce, L. (2016, March 22). Yes, I'm and American and no, I'm not a Trump supporter. Odyssey. Retrieved from https://www.theodysseyonline.com/yes-american-and-not-trump-supporter.

Chen, A. S., Wu, I., \& Bian, M. (2014). The moderating effects of active and agreeable conflict management styles on cultural intelligence and cross-cultural adjustment. International Journal of Cross Cultural Management, 14(3), 270-288. 
Dolby, N. (2004). Encountering an American self: Study abroad and national identity. Comparative Education Review, 48(2), 150-173.

Drury, B. J., Siy, J. O., \& Cheryan, S. (2011). When do female role models benefit women? The importance of differentiating recruitment from retention in STEM. Psychological Inquiry, 22(4), 265-269.

Earley, P. C., \& Ang, S. (2003). Cultural Intelligence: Individual interactions across cultures. Palo Alto, CA.: Stanford University Press

Eaton, W. W., Smith, C., Ybarra, M., Muntaner, C., \& Tien, A. (2004). "Center for Epidemiologic Studies Depression Scale: review and revision (CESD and CESD-R)." In M. E. Maruish (Ed.). The use of psychological testing for treatment planning and outcomes assessment, Vol. 3: Instruments for adults (3rd ed.; pp. 363-377). Mahwah, NJ: Lawrence Erlbaum.

Gieser, J. D. (2015). A sociocultural investigation of identity: How students navigate the study abroad experience. Journal of College Student Development, 56(6), 637-643.

Goldstein, S. B., \& Keller, S. R. (2015). U. S. College students' lay theories of culture shock. International Journal of Intercultural Relations, 47, 187-194.

Goldstein, S. B., \& Kim, R. I. (2006). Predictors of U. S. college students' participation in study abroad programs: A longitudinal study. International Journal of Intercultural Relations, 30, 507-521.

Huff, K. C. (2013). Language, cultural intelligence and expatriate success. Management Research Review, 36(6), 596-612.

Inzlicht, M., \& Ben-Zeev, T. (2000). A threatening intellectual environment: Why females are susceptible to experiencing problem-solving deficits in the presence of males. Psychological Science, 11, 365371.

Johns, M., Schmader, T, \& Martens, A. (2005). Knowing is half the battle: Teaching stereotype threat as a means of improving women's math performance. Psychological Science 16(3),175-179.

Kauffman, G. (2016, December 22). US students abroad emerge as unofficial ambassadors for Trump's America. The Christian Science Monitor. Retrieved from http://www.csmonitor.com/World/2016/1222/US-students-abroad-emerge-as-unofficialambassadors-for-Trump-s-America.

Kennedy, P. (2016, January 4). How Donald Trump is making it harder to be an American abroad. Vice. Retrieved from https://www.vice.com/en_us/article/how-donald-trump-makes-it-harder-to-be-anamerican-abroad.

Matsumoto, D. \& Hwang, H. C. (2013). Assessing cross-cultural competence: A review of available tests. Journal of Cross-cultural Psychology, 44(6), 849-873.

Mclntyre, R. B., Paulson, R. M., Taylor, C. A., Morin, A. L., \& Lord, C. G. (2011). Effects of role model deservingness on overcoming performance deficits induced by stereotype threat. European Journal of Social Psychology, 41(3), 301-311.

Miller, W. C., Anton, H. A., Townson, A. F. (2008). Measurement properties of the CESD scale among individuals with spinal cord injury. Spinal Cord, 46, 287-292.

Meyer-Lee, E., \& Evans, J. (2008, May). New tools for intercultural outcomes learning assessment. In D. Deardorff (Chair), Assessment toolbox for international educators. Symposium presented at the NAFSA Annual Conference, Washington, DC.

Ng, K. Y., Van Dyne, L., \& Ang, S. (2012). "Cultural intelligence: A review, reflections, and recommendations for future research.” In A. M. Ryan, F. T. Leong, \& F. L. Oswald (Eds.), Conducting multinational research: Applying organizational psychology in the workplace (pp. 2958). Washington, DC: American Psychological Association.

Nguyen, H. D., \& Ryan, A. M. (2008). Does stereotype threat affect test performance of minorities and women? A meta-analysis of experimental evidence. Journal of Applied Psychology, 93(6), 13141334.

Phinney, J. S., \& Ong, A. D. (2007). Conceptualization and measurement of ethnic identity: Current status and future directions. Journal of Counseling Psychology, 54(3), 271-281. 
Ployhart, R. E., Ziegert, J. C., \& McFarland, L. A. (2003). Understanding racial differences on cognitive ability tests in selection contexts: An integration of stereotype threat and applicant reactions research. Human Performance, 16, 231-259.

Pronin, E., Steele, C. M., \& Ross, L. (2004). Identity bifurcation in response to stereotype threat: Women and mathematics. Journal of Experimental Social Psychology, 40, 142-168.

Radloff, L. S. (1977). CES-D scale: A self-report depression scale for research in the general populations. Applied Psychological Measurement, 1, 385-401.

Sato, D. C. (2009). When worlds collide: Evaluating the impact of short-term study abroad programs (Doctoral Dissertation). Retrieved from EBSCOhost, search.ebscohost.com/login.aspx?direct=true \&db=eric \&AN=ED528480\&site=ehost-live.

Savicki, V., \& Cooley, E. (2011). American identity in study abroad students: Contrasts, changes, correlates. Journal of College Student Development, 52(3), 339-349.

Schmader, T. (2002). Gender identification moderates stereotype threat effects on women's math performance. Journal of Experimental Social Psychology, 38, 194-201.

Schwartz, S. J., Park, I. J. K., Huynh, Q.-L., Zamboanga, B. L., Umaña-Taylor, A. J., Lee, R. M., Rodríguez, L., Kim, S. Y., Whitbourne, S. K., Castillo, L. G., Weisskirch, R. S., Vazsonyi, A. T., Williams, M. K., \& Agocha, V. B. (2012). The American Identity Measure: Development and validation across ethnic group and immigrant generation. Identity: An International Journal of Theory and Research, 12(2), 93-128.

Sekaquaptewa, D., \& Thompson, M. (2003). Solo status, stereotype threat, and performance expectancies: Their effects on women's performance. Journal of Experimental Social Psychology, 39, 68-74.

Shaffer, E. S., Marx, D. M., \& Prislin, R. (2013). Mind the gap: Framing of women's success and representation in STEM affects women's math performance under threat. Sex Roles 68(7-8), 454463.

Smith, C. E., \& Hopkins, R. (2004). Mitigating the impact of stereotypes on academic performance: The effects of cultural identity and attributions for success among African American college students. The Western Journal of Black Studies, 28(1), 312-321.

Spencer, S. J., Logel, C., \& Davies, P. G. (2016). Stereotype threat. Annual Review of Psychology, 67, 415-437.

Steele, C. M., Spencer, S. J., \& Aronson, J. (2002). Contending with group image: The psychology of stereotype and social identity threat. In M. Zanna (Ed.), Advances in experimental social psychology (Vol. 34, pp. 379-440). New York: Academic Press.

Sturm, M. (2017, March 10). US politics trump abroad conversation: Students share experiences. The Lafayette. Retrieved from https://www.lafayettestudentnews.com/blog/2017/03/10/us-politics-trumpabroad-conversation-students-share-experiences.

Templer, K. J., Tay, C., \& Chandrasekar, N. A. (2006). Motivational cultural intelligence, realistic job preview, realistic living conditions preview, and cross-cultural adjustment. Group \& Organization Management, 31(1), 154-173.

Van Dyne, L., Ang, S., \& Koh, C. (2008). Development and validation of the CQS: The cultural intelligence scale. In S. Ang, \& L. Van Dyne, (Eds.) Handbook on Cultural Intelligence: Theory, Measurement and Applications (pp. 16-38). Armonk, NY: M.E. Sharpe.

Van Dyne, L., Ang, S., Ng, K.-Y., Rockstuhl, T., Tan, M. L., \& Koh, C. (2012). Sub-dimensions of the four factor model of cultural intelligence: Expanding the conceptualization and measurement of cultural intelligence (CQ). Social and Personal Psychology: Compass, 6(4), 295-313.

Villarreal, A. (April 5, 2016). Voices: Why I'm embarrassed to be an American while studying abroad. USA Today. Retrieved from http://college.usatoday.com/2016/04/05/voices-embarrassed-americanwhile-studying-abroad/

von Hippel, C., Walsh, A. M., \& Zouroudis, A. (2011). Identity separation in response to stereotype threat. Social Psychological and Personality Science, 2(3), 317-324.

Walton, G. M., \& Cohen, G. L. (2003). Stereotype lift. Journal of Experimental Social Psychology, 39, $456-467$. 
Walton, G. M., Logel, C., Peach, J. M., Spencer, S. J., \& Zanna, M. P. (2014). Two brief interventions to mitigate a "chilly climate" transform women's experience, relationships, and achievement in engineering. Journal of Educational Psychology, 107(2), 468-485.

Ward, C., Bochner, S., \& Furnham, A. (2001). The psychology of culture shock (2nd ed.). East Sussex, UK: Routledge. 